\title{
The Role of Trade Liberalization in Carbon Dioxide Emission: Evidence From Heterogeneous Panel Estimations
}

\author{
Gholamreza Zandi ${ }^{1}$ \& Muhammad Haseeb ${ }^{2}$ \\ ${ }^{1}$ Universiti Kuala Lumpur Business School, Malaysia \\ ${ }^{2}$ Taylors Business School (TBS), Taylors University Lakeside Campus, 1 Jalan Taylors Subang Jaya Selangore \\ Malaysia \\ Correspondence: Dr. Muhammad Haseeb, Taylors Business School (TBS), Taylors University Lakeside Campus, 1 \\ Jalan Taylors Subang Jaya Selangore Malaysia
}

Received: April 30, 2019

Accepted: May 30, 2019

Online Published: June 10, 2019

doi:10.5430/ijfr.v10n5p228

URL: https://doi.org/10.5430/ijfr.v10n5p228

\begin{abstract}
In the present globalized world, production forms are progressively divided across nations. Consequently, domestic consumption in one nation is progressively fulfilled by worldwide supply chains. This spectacle has pulled policy and widespread intellectual discussions on the assignment of greenhouse gas (GHG) emanations, especially carbon dioxide (CO2) emission; these are accountabilities connected to global trade since worldwide trade causes net carbon dioxide emission. The aim of the present study is to examine the impact of trade liberalization on carbon dioxide emission. We used the panel data of 105 developed and developing countries from 1990 to 2017 . The results of FMOLS and DOLS confirm that all variables are connected in the long-run period. The results of long run coefficient confirm that that the trade liberalization has a positive effect on environmental degradation and cause to increase environmental degradation. Likewise, economic growth and energy consumption has also a positive and significant impact on environmental degradation. However, we find an evidence of negative and significant impact of renewable energy utilization on environmental degradation. Finally, the results of heterogeneous panel causality confirm that there is a uni-directional causal relationship between trade liberalization and environmental degradation where causality is running from trade liberalization to environmental degradation. However, we find a bi-directional causal relationship of environmental degradation with energy utilization and renewable energy utilization in all selected developed and developing countries.
\end{abstract}

Keywords: trade liberalization, environmental degradation, renewable energy, heterogenous panel estimations

\section{Introduction}

The growing inclinations for globalized economies have resulted into numerous economic benefits. Such benefits are valuable in terms of raising country's enhanced foreign investments, technological advancements and economies of scale (Shahbaz, Khraief, Rehman, \& Zaman, 2016). However, the excess production demand resulted from augmented globalization have also encouraged several pressures on social and environmental conditions (Baars, Dannefer, Phillipson, \& Walker, 2016; Ozkurt \& Alpay 2018). The negative consequences of mass production in globalized economies are highlighted in terms of augmented inequality, uneven development, forced labors, child labors, waste abundance, air and water pollution, higher energy utilization and resource depletion (Kauder, \& Potrafke, 2015; Daly, Ullah, Rauf, \& Khan, 2017; Pazil, 2018).

In similar context, the role of trade liberalization is renowned for inducing numerous changes in country's social structure along with adverse environmental disruption (Al-Mulali, Weng-Wai, Sheau-Ting, \& Mohammed, 2015; Hakimi, \& Hamdi, 2016; Perera, 2018). In theory, trade liberalization has the potential to carry both positive and negative influences on environmental condition. Such effects can be distributed into three major domains of scale effect, technique effect and composition effect (Grossman, \& Krueger, 1993; Pamornmast,Jermsittiparsert \& Sriyakul 2013). The dominancy of scale effect is illustrated to portray adverse changes in the environment resulted from augmented economic activities, particularly when the nature of such activities remains unchanged. On the other hand, the domain of technique effect is renowned to carry positive impact on the environment emerged from the enhanced levels of income that encouraged eco-friendly methods of production and processes. Lastly, the 
composition effect is demonstrated by the alteration in the levels of output that have caused environmental pollution induced from trading activities (Managai, 2004; Wizarat \& Hye 2010).

The economic benefits of trade freedom are eminent in both developed and developing countries, however, the existing literature in deciding the precise contribution of trade liberalization on environmental condition is ambiguous (Ertugrul, Cetin, Seker, \& Dogan, 2016; Nemati, Hu, \& Reed, 2019). Several investigations have reported the negative relationship among numerous measures of environmental conditions with trade. These include the examinations of Andersson, (2018), Shahzad, Kumar, Zakaria, \& Hurr, (2017) and Al-Mulali, et al., (2015) concluded the positive impact of trade liberalization on environmental condition. On the other hand, Antweiler, Copeland, \& Taylor (2001) utilizing sulphur dioxide to measure degradation established that higher levels of trade liberalization resulted into augmented environmental quality through technique effect. Hence, the authors concluded that greater trade freedom is suitable for ecological improvements. Similar findings were reported by Shahbaz, Nasreen, Ahmed, \& Hammoudeh, (2017), Saidi, \& Mbarek, (2017) and Ali, Law, \& Zannah, (2016); in determining the link between trade openness and carbon emission concluding that advanced trade openness reduced the levels of carbon emanations and protect from environmental degradation.

Thus, the presence of amalgamated findings and the growing interest in researchers for analyzing trade-environment link makes the topic worthy to be re-investigated with higher generalization. In this regard, the role of panel investigations is crucial for providing superior insights into the conclusive association among the variables of interest by portraying advanced methodological generalization. The importance of studying trade-environment nexus is also crucial from the perspective of policy guidelines. In the present world, there still exist many countries that do not have sound environmental policies. The absence of an effective environmental policy in this regard, might also be the reason of having consecutive failures in determining trade-climate association (Shahbaz, et. al., 2007; Pamornmast, Jermsittiparsert \& Sriyakul 2013; Wu \& Pei 2018).

Therefore, observing the critical role of trade liberalization in influencing environmental condition, the current investigation aims to analyze the relationship between trade openness and environmental degradation. Several measures of environmental degradation have been utilized in prevailing literature such as Sulphur-di-oxide (Antweiler, et al., 2001; Panayotou, 1997), Nitrogen oxide (Cole, 2003; Cole, \& Elliott, 2003; Pamornmast, Jermsittiparsert \& Sriyakul 2013; Xu \& Zhang 2018), Ecological footprint (Sharif, Afshan, \& Qureshi, 2019; Ozturk, Al-Mulali, \& Saboori, 2016), etc. However, the consensus of the majority of the literature lies in measuring environmental degradation from the levels of carbon-di-oxide emanation. Following the literature, the present study investigated ecological degradation by utilizing the proxy of carbon emanation measured in Kilo tons of oil equivalent (KTOE). In addition, the current investigation is not limited to investigate any single country to generalize its results. The present study followed panel investigation of analyzing 105 developing and developed countries to strengthen the reliability of the derived association. Moreover, the current study applied sophisticated method of identifying cross sectional dependence among the data by applying Cross sectional dependence test introduced by Pesaran (2004). In addition, the current study also applied Bootstrapping cointegration introduced by Westerlund (2007). Finally, for capturing the long-run estimates of the variables under examination, the authors applied the econometrics of panel Fully Modified Ordinary Least Square (FMOLS) and Dynamic Ordinary Least Square (DOLS) Approaches that have been utilized in recent quality investigations of Sharif, Raza, Ozturk \& Afshan, (2019), Shahbaz, et al., (2007), Jebli, \& Youssef, (2017), Liu, Zhang, \& Bae, (2017), Bilgili, Koçak, \& Bulut, (2016) etc. The utilization of novel methodologies would help to enhance results reliability and aid in the process of policy formations.

The remaining of the paper has been outlined as below. Section two presents review of the literature regarding trade-climate association. Section three demonstrates utilized methodology of the current study. Section four presents empirical findings and results interpretations. Lastly, section five concludes the study and provides policy recommendations.

\section{Literature Review}

The relationship between economic indicators and environment has been the area of interest for many researchers; especially in last two decades. Various studies have been attributed to analyze the link between country's economic, social, political and environmental indicators. Keeping in mind the eminent role of trade in affecting environmental condition, Cetin, Seker, \& Cavlak, (2015) examined the relationship between trade liberalization and environmental degradation. The study utilized the panel data of newly industrialized economies from 1971 to 2010 . For ecological deterioration, the study used the substitute of $\mathrm{CO} 2$ emanations. Applying the econometrics of panel cointegration and granger causality, the outcomes of the study established that unit increase in trade liberalization tends to enhance 
carbon emanations by $0.53 \%$. On the other hand, the results of causal investigation have also reported that trade liberalization is uni-directionally linked to environmental degradation in the sampled countries.

Similarly, Mrabet, \& Alsamara, (2017) also examined the relationship between trade liberalization and environmental degradation. The study utilized the timeseries data of Qatar from 1980 to 2011. For ecological deterioration, the study used two proxies i.e. carbon emanations and ecological footprints. Applying the econometrics of ARDL methods, the outcomes of the study established the all the variables are integrated in long-run. In addition, the outcomes validated the presence of EKC curve for ecological footprint as an indicator of environmental degradation. Opposingly, the outcomes of carbon emanation as an indicator of degradation failed to validate the existence of inverted U-shaped EKC curve for the case of Qatar.

In a panel investigation, Managi, (2004) examined the relationship between trade liberalization and environmental degradation. The study utilized the panel data of sixty four emerging and developed nations from 1980 to 2014. For ecological deterioration, the study used the substitute of carbon emission. Applying the econometrics of panel regression, the outcomes of the study established that trade openness has a significant positive impact on environmental degradation. In particular, the findings suggested that unit increase in trade liberalization tends to enhance carbon emanations by $0.58 \%$ in the sampled countries. In another panel study, Shahbaz, et. al., (2017) also analyzed the association between trade liberalization and environmental degradation. The study utilized the three groups panel of 105 high, middle and low income economies from 1980 to 2011. For ecological deterioration, the study used the substitute of carbon emanations. Applying the econometrics of panel cointegration and VECM granger causality, the findings of the study established that both variables are integrated in long-run. In addition, the outcomes also suggested that trade openness is negatively related to carbon emanations in all samples. On the other hand, the results of causal investigation suggested that carbon emanation and trade liberalization have a bi-directional causal association in the global panel and middle income economies. Furthermore, for high and low income economies, the study confirmed the existence of uni-directional causal link running from trade liberalization to environment.

In another panel study, Kim, Suen, \& Lin, (2019) analyzed the association between trade and environmental degradation. The study utilized the panel data of 103 developed and developing economies to be grouped into four categories of North-North, South-South, North-South and South-North; from 1960 to 2013. For measure ecological deterioration, the study measure of $\mathrm{CO} 2$. Applying the econometrics of panel quantile and GMM approach, the findings of the study established that both variables are significant to influence each other. In particular, the outcomes suggested that trade with North enhances environmental degradation but trade with South eliminates it. On the other hand, the results of developed economies indicated that trade with both northern and southern economies bring positive impact on the environment. Finally, the analysis supported the validity of EKC curve but concluded that trade openness is a beneficial feature for advanced economies but in emerging countries it hurts the environmental quality.

Likewise, Ertugrul, et. al., (2016); Patnaik \& Pillai (2017) also discovered the association between trade liberalization and environmental degradation. The study utilized the panel data of 10 top carbon emitting emerging nations from 1971 to 2011. For ecological deterioration, the study used the measure of CO2 emanations. Applying the econometrics of ARDL bound testing and panel VECM, the findings of the study established that both variables are integrated in long-run in the two third of the sample. In addition, the outcomes also suggested that trade openness along with energy consumption and incomes are the vital drivers of degradation. On the other hand, the results of causal investigation suggested that carbon emanation and trade liberalization have a bi-directional causal association for the case of Korea, China and Brazil.

For Chinese trade, Andersson (2018) also analyzed the association between trade liberalization and environmental degradation. The study utilized the data of nineteen economies from 1995 to 2008. For ecological deterioration, the study used the measure of $\mathrm{CO} 2$ emanations. Applying the econometrics of panel regression, the findings of the study established that trade openness, weak ecological laws, legal rights \& foreign exchange policy have significant impact on environmental degradation. In particular, the outcomes suggested that trade openness is positively related to carbon emanations in majority countries. For Pakistan, Shahzad, et al., (2017) investigate the connection between trade liberalization, energy utilization, financial advancements and environmental degradation. They used the data from 1971 to 2011. For ecological deterioration, the study used the measure of CO2 emanations. Applying the econometrics of ARDL bound testing, the findings validated the presence of EKC curve for Pakistan. In addition, the results exhibited that trade openness and financial advancements are positively related to carbon emanations. On the other hand, the results of causal investigation suggested that carbon emanation and rest of the variables have a 
uni-directional association where the direction of causality runs from trade liberalization, financial advancements and energy utilization to environmental degradation.

Le, Chang, \& Park, (2016) also examined the association between trade liberalization, energy utilization, financial advancements and environmental degradation. The study utilized the panel data of ninety eight countries from 1990 to 2013. For environmental condition, the study used the measure of particulate matter $10 \mu \mathrm{m}$ (PM10). Applying the econometrics of panel cointegration, the findings established the significance of trade liberalization in driving degradation at global level. On the other hand, the results of causal investigation suggested that environmental degradation and trade openness have a bi-directional causal association in the sampled countries. Furthermore, $\mathrm{Li}$, Xu, \&, Yuan, (2015); Perera, Johnson \& Hewege (2018) also analyzed the relationship between trade liberalization and environment. The study utilized the panel data of 131 developed and developing countries from 1961 to 2004. For ecological deterioration, the study used the measure of air visibility. Applying the econometrics of panel regression, the findings validated the presence of significant association among the variables. In addition, the results exhibited that trade openness is a crucial driver of environmental degradation and declines air quality in both advanced and emerging economies.

For Malaysia, Ling, Ahmed, Muhamad, \& Shahbaz, (2015) examined the association between trade liberalization, energy utilization and environmental degradation. They used the data from 1970 to 2011. For ecological deterioration, the study used the measure of $\mathrm{CO} 2$ emanations. Applying the econometrics of ARDL bound testing, the findings validated the presence of EKC curve for Malaysian economy. In addition, the results exhibited that that trade openness is positively related to carbon emanation and helps to control environmental degradation. Likewise, Saidi, \& Mbarek, (2017) also investigated the relationship between trade liberalization, urbanization, financial advancements and environmental degradation. The study utilized the data of nineteen economies from 1990 to 2013. For ecological deterioration, the study used the measure of $\mathrm{CO} 2$ emanations. Applying the econometrics of panel cointegration, the findings failed to validate the presence of EKC curve for the sampled countries. In addition, the results exhibited that that urbanization and financial advancements are negatively related to carbon emanations. On the other hand, the results of the study failed to find the significant contribution of trade liberalization in influencing environmental degradation.

For Asian economies, Duong, \& Hultberg, (2018) examined the association between trade liberalization, output growth and environmental degradation. The study utilized the data of Asian emerging economies from the period of 1986 to 2013. Applying theoretical trade model, the findings validated the presence of EKC curve. In addition, the results exhibited that trade openness enhanced environmental degradation. Opposingly, the outcomes also concluded that augmentation in country's imports through advanced technology could drive environmental quality and helped to resolve growing environmental pressures. As for Nigeria, Ali, Law, \& Zannah, (2016) examined the association between trade liberalization, energy utilization, urbanization, output growth and environmental degradation. The study focused the data from 1970 to 2011. For ecological deterioration, the study used the measure of CO2 emanations. Applying the econometrics of ARDL approach, the findings validated the significance association of trade, output and energy utilization with environmental degradation in Nigeria. On the other hand, the findings of the study failed to find the significant contribution of urbanization in affecting degradation. In addition, the results exhibited that trade openness have a negative impact on carbon emanations, however, increase in output growth and energy utilization enhanced degradation of the country.

Moreover, Bernard, \& Mandal, (2016) also examined the association between trade liberalization and environmental degradation. The study utilized the panel data of sixty emerging economies from 2002 to 2012. For environmental condition, the study used two proxies i.e. carbon emanations and environmental performance index (EPI). The empirical findings of the study were derived by applying the methods of panel regression and GMM Approaches. The findings of fixed effect indicated that trade liberalization improved ecological performance through EPI but also enhanced carbon emanations. Correcting the endogeneity revealed the insignificant role of trade openness in influencing environment through EPI but it confirmed the positive association with carbon emanations. On the other hand, the results from GMM method highlight the detrimental role of EPI in influencing environment. The results also concluded that augmentation in carbon emanations, trade liberalization, energy utilization and income have deadly impact on environmental condition. As for Tunisia, Farhani, \& Ozturk, (2015) examined the causal association between trade liberalization, energy utilization, output, financial advancements, urbanization and environmental degradation. They used the data from 1971 to 2012. For ecological deterioration, the study used the measure of $\mathrm{CO} 2$ emanations. Applying the econometrics of ARDL bound testing and VECM approaches, the findings of the study failed to validate the significance of EKC curve for Tunisia. In addition, the outcome of the study found that output, urbanization and financial advancements are positively associated with environmental 
degradation in long-run. Opposingly, the findings established the negative and significant connection of trade liberalization and energy consumption with carbon emanations in Tunisia. As for causal investigation, the authors reported that long-run causal association between carbon emission and financial advancements and between carbon emission and trade openness for the country.

Moreover, Al-Mulali, \& Ozturk, (2015) also inspected the relationship between energy utilization, political instability, industrial growth, urban development, trade liberalization and environmental degradation in MENA countries. To analyze the connection, the authors utilized the information of fourteen MENA countries from 1996 to 2012. For environmental degradation, the study used the measure of ecological footprint. The findings of the analyses applying the method of FMOLS established the significant relationship of energy utilization, trade liberalization, urban development, industrial growth and political instability with environment. In particular, the findings of the analysis suggested that trade, energy, industrial development and urbanization are positively associated with degradation, whereas, political stability declined ecological damage. Utilizing the similar measure of degradation, Al-Mulali, et. al., (2015) also observed the relationship of trade liberalization with environment. Studying the panel of ninety three economies between the period of 1980 to 2008, the results of the study reported that trade openness enhanced environmental damage in the sampled countries.

\section{Methodology}

In the present exploration, we use annual data of trade liberalization, economic growth, energy utilization, renewable energy utilization and carbon dioxide emissions. The trade liberalization is represented by (TL). Besides, energy utilization is represented by (ENC). Likewise, renewable energy utilization is represented by (REN). Moreover, gross domestic product that is utilized as a substitute of economic growth and represented by (GDP). Finally, carbon dioxide emission is utilized as an intermediary of environmental degradation which is utilized as a (CO2). The information of trade liberalization is gathered from the website of International Monetary Fund (IMF). Moreover, the data of energy utilization, renewable energy utilization, carbon dioxide emanation and economic growth are gathered from the site of the World Bank (World Development Indicator). The present examination is exploring the impact of trade liberalization, renewable, economic growth and energy utilization in 105 developed and developing countries across the world. In the present examination, we use energy utilization, renewable energy utilization, economic growth and trade liberalization as a determinant of carbon dioxide emission in various developing and developed nations. Furthermore, the present examination covers the time extends from 1990 to 2017 for 105 developing and developed countries. In the present examination, the carbon dioxide emission is shown by the beneath equation:

$$
C O 2_{i t}=f\left(T L_{i t}, E N C_{i t}, R E N_{i t}, G D P_{i t}\right)
$$

In the above equation, $\mathrm{CO} 2$ it is the carbon dioxide emission and measure in (kilotons of oil equivalent), TLit is trade liberalization. ENCit is energy utilization which is estimated by total energy consumption from all sources, RENit is estimated as renewable energy utilization and measured as percentage of renewable power utilization out of aggregate power utilization. Finally, GDPit is the economic growth which is estimated as all final finished goods and services. Finally, i talks about the number of developing and developed countries use in the present examination and $\mathrm{t}$ clarifies the time allotment of the present examination. In an ongoing study, we investigate the long haul association among the components by applying a panel long-run relationship technique. Correspondingly, the present examination clarifies the long-run effect of trade liberalization, energy and renewable energy utilization and economic growth on carbon dioxide emission by using FMOLS and DOLS approaches. Finally, we use another strategy for heterogeneous causality investigation to deal with assess the noticeable causal association among carbon dioxide emission, economic growth, energy and renewable energy utilization and trade liberalization in 105 developed and developing countries.

\subsection{Panel Unit Root Tests}

In the current study, we use Levin, Lin and Chu (2002) and IM, Pesaran and Shin (2003) unit root test which focusses on the theory of integration of variables. This panel unit root test is the key to apply panel long run relationship systems. This methodology is utilized to research the pattern of integration of the components. For example, if every single chosen factor are not stationary of the level, for instance $\mathrm{I}(0)$, by then this implies the majority of the variables have a unit root issue at level and are stationary at first differential arrangement.

\subsection{CD and CIPS Test}

At second stage, we check that which of the variable has the features for cross-sectional independence or dependence. This is the reason which should be unravelled before applying to basic estimations. The traditional unit root test has low power and is not viable when they are utilized on the panel estimations which as of now has a cross-sectional 
reliance problem (Bhattacharya et al., 2016; Sharif et al., 2019). Thus, in current investigation, we also utilize Pesaran (2007) CIPS unit root test which depends on the theory of cross-sectional reliance. This test is utilized to inspect the order of joining of the factors. On the other hand, if whole factors are coordinated of the equivalent level for example I(1), at that point this means whole of the informational collection has a unit root issue at level and are stationary at first differential series. In this way, it tends to be finished up that all factors in the informational collection may have a relationship in long-run symmetry.

\subsection{Traditional Panel Cointegration Tests}

We apply Kao (2003) and Pedroni (2004) panel long-run relationship procedures to investigate the long-haul connection between TE, ENC, REN and CO2 in developed and developing countries. So as to run this approach, every factor ought to be stationary at first differential for example I(1).

\subsection{Bootstrap Panel Cointegration Tests}

In the present investigation, we also utilize bootstrap cointegration introduced by Westerlund (2007) to analyse the long-term connection between the factors all through the total sample of 105 developing and developed countries. This examination is increasingly valuable if the time arrangement segment of each cross-segment is lesser. Inferable from these highlights look into researchers have recently adopting the bootstrapping long run relationship method to explore the long-term connection among different factors (Sharif et al. 2019). The results reveal that these tests have limiting normal distribution and they are progressively dependable in term of constancy. Westerlund (2007) clarifies that the results provide nice size correctness and are additionally influential that traditional cointegration test by Pedroni (2004). In light of this proof, present investigation will dissect the impact of trade liberalization, energy utilization and renewable energy utilization and economic growth on carbon dioxide emission in selected developed and developing countries. In light of the existence of long-run relationship, the long-run estimation remains calculated. In a cross-sectional examination, the error fluctuation changes over the groups which effect the consistence of the parameters. So as to adapt up this issue the generalized least squares strategy (GLS) could be used. In any case, the difference consistency still happens, for example, the relationship of the squared residuals with the regressor in each group. As such, to deal with the issue giving the issue of heteroskedasticity, we finally apply fully modified ordinary least square (FMOLS) and dynamic ordinary least square (DOLS) methods.

\subsection{Long Run Estimations}

Previous investigation utilizes pooled conventional least squares (OLS) to look at the effect of considered variables. Moreover, Pedroni (2001a, 2001b) opposed that as a result of regression result, inconsistent controls could affect for the presence of sequential correlation and endogeneity issue among the regressor. Likewise, to deal with these issues, the present examination uses the FMOLS procedure. This system focuses on the non-parametric strategy so as to choose the issue of endogeneity and sequential correlation (Sharif et al, 2019). In like way, we use FMOLS and DOLS methodologies to examine the long-haul association among trade liberalization, energy utilization, carbon dioxide emission, economic growth and renewable energy utilization in developed and developing countries. The long-term connection between the variable is explained by utilizing the FMOLS and DOLS approaches. These approaches were displayed by Phillips and Hansen (1990) and sometime later adjusted by the Pedroni (2001). We select these methods since they talk about to autocorrelation and endogeneity issues and provide robust outcomes.

\section{Data Analysis and Discussion}

In this section, we explain the results attained by data analysis. Table 1 describes the outcomes for the two different unit root test. The unit root test results for the 105 developing and developed countries exhibit that the refusal of the null hypothesis of unit root test at the $1 \%$ significance level for all variables, implying that each of the variable are non-stationary at current and become stationary at difference stage. Therefore, the results of unit root confirm that each of the selected variables are showing up non-stationary property at the level series and exhibiting stationary properties at the first difference stage. In general, all components are integrated at I(1). Thusly, there must be a sign of long-run association between the components in long run. 
Table 1. Results of stationary test

\begin{tabular}{lllllllll}
\hline \multirow{2}{*}{ Variables } & \multicolumn{2}{l}{ IM, Pesaran and Shin } & \multicolumn{5}{l}{ Levin, Lin and Chu } \\
\cline { 2 - 9 } & $\mathbf{I}(\mathbf{0})$ & & $\mathbf{I}(\mathbf{1})$ & $\mathbf{I}(\mathbf{0})$ & & $\mathbf{I}(\mathbf{1})$ \\
\cline { 2 - 9 } & $\mathbf{C}$ & $\mathbf{C \& T}$ & $\mathbf{C}$ & $\mathbf{C \& T}$ & $\mathbf{C}$ & $\mathbf{C \& T}$ & $\mathbf{C}$ & $\mathbf{C \& T}$ \\
\hline CO2 & 0.338 & 0.327 & $-5.938 * * *$ & $-5.887 * * *$ & 0.344 & 0.312 & $-5.483 * * *$ & $-5.389 * * *$ \\
\hline TL & 0.893 & 0.802 & $-5.201 * * *$ & $-5.198 * * *$ & 0.778 & 0.736 & $-5.117 * * *$ & $-5.139 * * *$ \\
\hline ENC & 0.593 & 0.583 & $-4.352 * * *$ & $-4.384 * * *$ & 0.521 & 0.529 & $-4.202 * * *$ & $-4.187 * * *$ \\
\hline REN & 0.346 & 0.339 & $-5.203 * * *$ & $-5.212 * * *$ & 0.321 & 0.330 & $-5.199 * * *$ & $-5.221 * * *$ \\
\hline GDP & -1.034 & -1.089 & $-5.082 * * *$ & $-5.077 * * *$ & -1.109 & -1.128 & $-5.110 * * *$ & $-5.098 * * *$ \\
\hline
\end{tabular}

Note: Single, double, and triple asterisks indicate significance level respectively at 1, 5, and $10 \%$.

Source: authors' estimation

Table 2 clarifies the results for the CD test and CIPS unit root test. The CD test results refused the invalid hypothesis of cross area independence, meaning sign of cross-sectional reliance among the dataset. We also utilized recently introduced CIPS unit root test. This test talks about for cross-sectional reliance in the information series. The results of the CIPS unit root test demonstrate that the refusal of the invalid hypothesis for all factors at first differentials. In this way, there must be an indication of cointegration connection between the factors in long-term equilibrium.

Table 2. Results of cross-sectional dependence and CIPS unit root test

\begin{tabular}{llllc}
\hline \multirow{2}{*}{ Variable } & CD test & p-value & \multicolumn{2}{c}{ CIPS test } \\
\cline { 2 - 5 } & & & Level & 1st difference \\
\hline CO2 & 8.362 & 0.0000 & -1.228 & $-6.364 * * *$ \\
\hline TL & 28.415 & 0.0000 & -1.088 & $-5.333 * * *$ \\
\hline ENC & 17.499 & 0.0000 & -2.119 & $-4.879 * * *$ \\
\hline REN & 20.382 & 0.0000 & -2.007 & $-6.413^{* * *}$ \\
\hline GDP & 18.429 & 0.0000 & -1.832 & $-6.248^{* * *}$ \\
\hline
\end{tabular}

Note: $* * *, * *, *$ indicates statistical significance at $1 \%, 5 \% \& 10 \%$.

Source: Authors' estimation.

Table 3 defines the outcomes of Pedroni panel cointegration analysis results. This approach rejects the null hypothesis of no cointegration at all seven estimations of within estimation (Panel v-stats, Panel rho-stats, Panel PP stats and Panel ADF stats) and three estimations of the between group (group rho, PP stats and group ADF stats) second this rejection of no cointegration in the favour of alternative hypothesis. Therefore, seven tests reveal that the variables move together over the long-haul relationship in trade liberalization, energy utilization, renewable energy utilization and economic growth in carbon dioxide emission model.

Table 3. Results of Pedroni (Engle-Granger based) panel cointegration

\begin{tabular}{lll}
\hline Estimates & Stats. & Prob. \\
\hline $\mathbf{C O 2}=\boldsymbol{f}$ (TL + ENC + REN + GDP) & & \\
\hline Panel v-statistic & -17.382 & 0.000 \\
\hline Panel rho-statistic & -14.320 & 0.000 \\
\hline Panel PP statistic & -11.384 & 0.000 \\
\hline Panel ADF statistic & -16.384 & 0.000 \\
\hline
\end{tabular}




\begin{tabular}{lll}
\hline \multicolumn{2}{l}{ Alternative Hypothesis: Individual AR Coefficient } \\
\hline Group rho-statistic & -14.832 & 0.000 \\
\hline Group PP statistic & -27.628 & 0.000 \\
\hline Group ADF statistic & -22.277 & 0.000 \\
\hline
\end{tabular}

Note: The null hypothesis of Pedroni's (1997) panel cointegration procedure is no cointegration

Source: Authors' estimation.

The cointegration among all factors also confirm by using the Kao test. As saw from the outcomes presented in Table 4, the null hypothesis is rejected and the alternative hypothesis is accepted, i.e., long-run relationship exists between TL, ENC, REN, GDP and CO2 in the 105 developed and developing nations.

Table 4. Results of Kao (Engle-Granger based) panel cointegration

\begin{tabular}{lll}
\hline Estimates & Stats. & Prob. \\
\hline CO2 $=\boldsymbol{f}($ TL + ENC + REN + GDP $)$ & & \\
\hline Panel ADF-statistics & -42.248 & 0.000
\end{tabular}

Note: The null hypothesis of Kao residual co-integration panel co-integration procedure is no co-integration

Source: Authors' estimation.

The long-term association among the factors is also examined by utilizing the advanced long-term cointegration test. The outcomes related the panel long-run relationship estimations are presented in Table 5. The outcomes also robusten the approval of alternative hypothesis. Consequently, the advanced cointegration test also endorses that economic growth, trade liberalization, energy utilization and renewable energy utilization are co move in the long-term symmetry in carbon emission framework.

Table 5. Results of Westerlund (2007) bootstrap panel cointegration

\begin{tabular}{lllll}
\hline Statistic & Value & $\mathbf{Z}$ value & $\boldsymbol{p}$ value & $\begin{array}{l}\text { Robust } \\
\text { value }\end{array}$ \\
\hline Gt & -2.781 & -1.229 & 0.000 & 0.000 \\
\hline Ga & -22.848 & -15.215 & 0.000 & 0.000 \\
\hline $\mathbf{P t}$ & -21.008 & -7.132 & 0.000 & 0.000 \\
\hline $\mathbf{P a}$ & -27.135 & -17.188 & 0.000 & 0.000
\end{tabular}

Note: The null hypothesis of Westerlund (2007) panel cointegration procedure is no cointegration.

Using the boot strap approach of Westerlund (2007) to account for cross-sectional dependence, the number of replications is 1000 . The $\mathrm{p}$-values are for a one-sided test based on normal distribution. The robust $\mathrm{p}$-value are for a one-sided test based on 1000 bootstrapping replications.

Source: Authors' estimation.

Present study examines the long-term checks by reporting the FMOLS and DOLS estimates. The consequences of FMOLS and DOLS have been shown to in Table 6. The long-run coefficient estimated applying two unique methods which are particularly significant at the $10 \%$ essentialness level. The results of FMOLS and DOLS confirm that every one of the determinants of carbon dioxide emission in the all selected developed and developing countries. The consequences of the long-run coefficient further recommend that every one of the determinants considered in this investigation significantly affect carbon dioxide emission. 
Table 6. Results of long-run estimation through FMOLS and DOLS

\begin{tabular}{lllllll}
\hline \multirow{2}{*}{ Variable } & \multicolumn{1}{l}{ FMOLS } & \multicolumn{5}{c}{ DOLS } \\
\cline { 2 - 7 } & Coeff. & t-stats & Prob. & Coeff. & t-stats & Prob. \\
\hline TL & 0.332 & 7.131 & 0.000 & 0.302 & 7.201 & 0.000 \\
\hline ENC & 0.402 & 3.982 & 0.000 & 0.421 & 3.893 & 0.000 \\
\hline REN & -0.245 & -3.875 & 0.000 & -0.221 & -3.899 & 0.000 \\
\hline GDP & 0.483 & 6.372 & 0.000 & 0.508 & 6.128 & 0.000 \\
\hline
\end{tabular}

Source: Authors Estimation.

Table 6 describe that the results of panel estimations approve that the long-term effect on carbon dioxide by trade liberalization to 0.332 explain that a per unit variation in the trade liberalization will increase carbon dioxide emission by 0.332 unit. The outcomes further suggested that ENC and GDP have also a positive and significant effect on $\mathrm{CO} 2$. The outcomes confirm that a per unit increase in energy utilization (economic growth) causes 0.402 (0.483) unit change in carbon dioxide emission. Finally, results also revealed that renewable energy utilization has a negative and significant impact on carbon dioxide emission. Results suggested that a per unit increase in renewable energy utilization causes 0.245 unit decrease in carbon dioxide emission in selected developed and developing countries.

In general, the consequences of FMOLS and DOLS affirm that trade liberalization, energy consumption, renewable energy utilization and economic growth are the critical and noteworthy determinants of carbon dioxide emission in all 105 developing and developed countries. The outcomes recommend that all selected developed and developing countries need environmental efficient energy utilization such as green energy utilization and sustainable economic development which is free of carbon pollution. The outcomes additionally affirmed that the energy utilization and economic growth significantly increase the environmental hazard. However, the utilization of renewable energy helps to reduce environmental degradation. Therefore, these countries can invest and expand more ingeneration of renewable energy and its consumption so, ultimately it will help to reduce the environmental degradation and enhance the sustainable development in their countries.

Table 7. Results of Heterogeneous panel causality test

\begin{tabular}{lll}
\hline Null Hypothesis & Zbar-Stat & Prob. \\
\hline TL does not homogeneously cause CO2 & 14.438 & 0.000 \\
\hline CO2 does not homogeneously cause TL & 1.213 & 0.671 \\
\hline ENC does not homogeneously cause CO2 & 10.789 & 0.000 \\
\hline CO2 does not homogeneously cause ENC & 13.278 & 0.000 \\
\hline REN does not homogeneously cause CO2 & 16.249 & 0.000 \\
\hline CO2 does not homogeneously cause REN & 27.198 & 0.000 \\
\hline GDP does not homogeneously cause CO2 & 8.879 & 0.000 \\
\hline CO2 does not homogeneously cause GDP & 0.156 & 0.827
\end{tabular}

Source: Authors Estimation.

Finally, we apply the heterogeneous panel causality to check the causal association among the trade liberalization, economic growth, carbon dioxide emission, energy utilization, and renewable energy utilization. The results of heterogenous panel causality are reported in Table 7 . The results show that a unidirectional causal connection occurs between the trade liberalization and carbon dioxide emission and the causality is running from trade liberalization to carbon dioxide emission however, the reverse not possible. On the other hand, in the carbon dioxide emission and energy utilization model, outcome signifies a bi-directional causal connection occurs between energy utilization and carbon dioxide emission. Results further suggest a bi-directional causal relationship between renewable energy 
utilization and carbon dioxide emission in the panel of developed and developing countries. The result also suggested a uni-directional causal relationship between carbon dioxide emission and economic growth where causality is running from economic growth to carbon dioxide emission. However, we do not find any evidence of causal relationship from carbon dioxide emission to economic growth in all selected 105 developed and developed countries.

\section{Conclusion}

The role of trade liberalization is renowned for inducing numerous changes in country's social structure along with adverse environmental disruption. In theory, trade liberalization has the potential to carry both positive and negative influences on environmental condition. Such effects can be distributed into three major domains of scale effect, technique effect and composition effect. The economic benefits of trade freedom are eminent in both developed and developing countries, however, the existing literature in deciding the precise contribution of trade liberalization on environmental condition is ambiguous. Several investigations have reported the negative relationship among numerous measures of environmental conditions with trade. Thus, the presence of amalgamated findings and the growing interest in researchers for analyzing trade-environment link makes the topic worthy to be re-investigated with higher generalization. In this regard, the role of panel investigations is crucial for providing superior insights into the conclusive association among the variables of interest by portraying advanced methodological generalization.

The importance of studying trade-environment nexus is also crucial from the perspective of policy guidelines. Following the literature, the present study investigated ecological degradation by utilizing the proxy of carbon emanation measured in Kilo tons of oil equivalent (KTOE). In addition, the current investigation is not limited to investigate any single country to generalize its results. The present study followed panel investigation of analyzing 105 developing and developed countries to strengthen the reliability of the derived association. Moreover, the current study applied sophisticated method of identifying cross sectional dependence among the data by applying Cross sectional dependence test introduced by Pesaran (2004). In addition, the current study also applied Bootstrapping cointegration introduced by Westerlund (2007). Finally, for capturing the long-run estimates of the variables under examination, the authors applied the econometrics of panel Fully Modified Ordinary Least Square (FMOLS) and Dynamic Ordinary Least Square (DOLS). The utilization of novel methodologies would help to enhance results reliability and aid in the process of policy formations. The results of FMOLS and DOLS confirm that trade liberalization, energy utilization and economic growth are the significant and positively impact on environmental degradation in all selected developed and developing countries. The results further suggested that renewable energy consumption is the only factor among all selected variable that have a negative and significant impact on environmental degradation. In general, the results of long run estimations confirm the renewable energy utilization help to reduce the environmental degradation in all selected developing and developed countries. Finally, the results of panel causality confirm a bidirectional causal relationship of carbon dioxide emission with renewable and non-renewable energy utilization however, an evidence uni-directional causality from trade liberalization and economic growth to carbon dioxide emission.

\section{References}

Ali, H. S., Law, S. H., \& Zannah, T. I. (2016). Dynamic impact of urbanization, economic growth, energy consumption, and trade openness on CO 2 emissions in Nigeria. Environmental Science and Pollution Research, 23(12), 12435-12443. https://doi.org/10.1007/s11356-016-6437-3

Al-Mulali, U., \& Ozturk, I. (2015). The effect of energy consumption, urbanization, trade openness, industrial output, and the political stability on the environmental degradation in the MENA (Middle East and North African) region. Energy, 84, 382-389. https://doi.org/10.1016/j.energy.2015.03.004

Al-Mulali, U., Weng-Wai, C., Sheau-Ting, L., \& Mohammed, A. H. (2015). Investigating the environmental Kuznets curve (EKC) hypothesis by utilizing the ecological footprint as an indicator of environmental degradation. Ecological Indicators, 48, 315-323. https://doi.org/10.1016/j.ecolind.2014.08.029

Andersson, F. N. (2018). International trade and carbon emissions: The role of Chinese institutional and policy reforms. Journal of Environmental Management, 205, 29-39. https://doi.org/10.1016/j.jenvman.2017.09.052

Antweiler, W., Copeland, B. R., \& Taylor, M. S. (2001). Is free trade good for the environment?. American Economic Review, 91(4), 877-908. https://doi.org/10.1257/aer.91.4.877

Baars, J., Dannefer, D., Phillipson, C., \& Walker, A. (2016). Aging, globalization and inequality: The new critical gerontology. Routledge. https://doi.org/10.4324/9781315225111 
Bernard, J., \& Mandal, S. K. (2016). The impact of trade openness on environmental quality: an empirical analysis of emerging and developing economies. WIT Transactions on Ecology and the Environment, 203, 195-208. https://doi.org/10.2495/EID160181

Bhattacharya, M., Paramati, S. R., Ozturk, I., \& Bhattacharya, S. (2016). The effect of renewable energy consumption on economic growth: Evidence from top 38 countries. Applied Energy, 162, 733-741. https://doi.org/10.1016/j.apenergy.2015.10.104

Bilgili, F., Koçak, E., \& Bulut, Ü. (2016). The dynamic impact of renewable energy consumption on CO2 emissions: a revisited Environmental Kuznets Curve approach. Renewable and Sustainable Energy Reviews, 54, 838-845. https://doi.org/10.1016/j.rser.2015.10.080

Cetin, M., Seker, F., \& Cavlak, H. (2015). The impact of trade openness on environmental pollution: A panel cointegration and causality analysis. In Regional Economic Integration and the Global Financial System (pp. 221-232). IGI Global. https://doi.org/10.4018/978-1-4666-7308-3.ch017

Cole, M. A. (2003). Development, trade, and the environment: how robust is the Environmental Kuznets Curve?. Environment and Development Economics, 8(4), 557-580. https://doi.org/10.1017/S1355770X0300305

Cole, M. A., \& Elliott, R. J. (2003). Determining the trade-environment composition effect: the role of capital, labor and environmental regulations. Journal of Environmental Economics and Management, 46(3), 363-383. https://doi.org/10.1016/S0095-0696(03)00021-4

Daly, V., Ullah, F., Rauf, A., \& Khan, G. Y. (2017). Globalization and unemployment in Pakistan. https://doi.org/10.18488/journal.aefr.2017.77.634.643

Duong, T., \& Hultberg, P. T. (2018). Trade Openness, Economic Growth, and Environmental Degradation in Asian Developing Countries. Journal of Applied Business and Economics, 20(5). https://doi.org/10.33423/jabe.v20i5.361

Ertugrul, H. M., Cetin, M., Seker, F., \& Dogan, E. (2016). The impact of trade openness on global carbon dioxide emissions: evidence from the top ten emitters among developing countries. Ecological Indicators, 67, 543-555. https://doi.org/10.1016/j.ecolind.2016.03.027

Farhani, S., \& Ozturk, I. (2015). Causal relationship between CO 2 emissions, real GDP, energy consumption, financial development, trade openness, and urbanization in Tunisia. Environmental Science and Pollution Research, 22(20), 15663-15676. https://doi.org/10.1007/s11356-015-4767-1

Grossman, G. M., \& Krueger, A. B. (1991). Environmental Impacts of a North American Free Trade Agreement. NBER Working Paper No. 3914. https://doi.org/10.3386/w3914

Hakimi, A., \& Hamdi, H. (2016). Trade liberalization, FDI inflows, environmental quality and economic growth: a comparative analysis between Tunisia and Morocco. Renewable and Sustainable Energy Reviews, 58, 1445-1456. https://doi.org/10.1016/j.rser.2015.12.280

Im, K. S., Pesaran, M. H., \& Shin, Y. (2003). Testing for unit roots in heterogeneous panels. Journal of Econometrics, 115(1), 53-74. https://doi.org/10.1016/S0304-4076(03)00092-7

Jebli, M. B., \& Youssef, S. B. (2017). The role of renewable energy and agriculture in reducing CO2 emissions: Evidence for North Africa countries. Ecological Indicators, 74, 295-301. https://doi.org/10.1016/j.ecolind.2016.11.032

Kauder, B., \& Potrafke, N. (2015). Globalization and social justice in OECD countries. Review of World Economics, 151(2), 353-376. https://doi.org/10.1007/s10290-015-0213-1

Kim, D. H., Suen, Y. B., \& Lin, S. C. (2019). Carbon dioxide emissions and trade: Evidence from disaggregate trade data. Energy Economics, 78, 13-28. https://doi.org/10.1016/j.eneco.2018.08.019

Le, T. H., Chang, Y., \& Park, D. (2016). Trade openness and environmental quality: International evidence. Energy Policy, 92, 45-55. https://doi.org/10.1016/j.enpol.2016.01.030

Levin, A., Lin, C. F., \& Chu, C. S. J. (2002). Unit root tests in panel data: asymptotic and finite-sample properties. Journal of Econometrics, 108(1), 1-24. https://doi.org/10.1016/S0304-4076(01)00098-7

Li, Z., Xu, N., \& Yuan, J. (2015). New evidence on trade-environment linkage via air visibility. Economics Letters, 128, 72-74. https://doi.org/10.1016/j.econlet.2015.01.014 
Ling, C. H., Ahmed, K., Muhamad, R. B., \& Shahbaz, M. (2015). Decomposing the trade-environment nexus for Malaysia: what do the technique, scale, composition, and comparative advantage effect indicate? Environmental Science and Pollution Research, 22(24), 20131-20142. https://doi.org/10.1007/s11356-015-5217-9

Liu, X., Zhang, S., \& Bae, J. (2017). The impact of renewable energy and agriculture on carbon dioxide emissions: Investigating the environmental Kuznets curve in four selected ASEAN countries. Journal of Cleaner Production, 164, 1239-1247. https://doi.org/10.1016/j.jclepro.2017.07.086

Managi, S. (2004). Trade liberalization and the environment: carbon dioxide for 1960-1999. Economics Bulletin, $17(1), 1-5$.

Mrabet, Z., \& Alsamara, M. (2017). Testing the Kuznets Curve hypothesis for Qatar: A comparison between carbon dioxide and ecological footprint. Renewable and Sustainable Energy Reviews, 70, 1366-1375. https://doi.org/10.1016/j.rser.2016.12.039

Nemati, M., Hu, W., \& Reed, M. (2019). Are free trade agreements good for the environment? A panel data analysis. Review of Development Economics, 23(1), 435-453. https://doi.org/10.1111/rode.12554

Ozkurt, B., \& Alpay, C. B. (2018). Investigation of Proactive Personality Characteristics of the Students of High School of Physical Education and Sports through Various Variables. Asian Journal of Education and Training, 4(2), 150-155. https://doi.org/10.20448/journal.522.2018.42.150.155

Ozturk, I., Al-Mulali, U., \& Saboori, B. (2016). Investigating the environmental Kuznets curve hypothesis: the role of tourism and ecological footprint. Environmental Science and Pollution Research, 23(2), 1916-1928. https://doi.org/10.1007/s11356-015-5447-x

Pamornmast, C., Jermsittiparsert, K., \& Sriyakul, T. (2013). An Empirical Discourse Analysis on Correlations between the Exchange Rate and Exports of Agricultural Product Export. PSAKU International Journal of Interdisciplinary Research, 2(1), 48-62. https://doi.org/10.12778/235108618X15452373185138

Pamornmast, C., Jermsittiparsert, K., \& Sriyakul, T. (2013). An Empirical Discourse Analysis on Correlations between the Exchange Rate and Exports. Social and Management Research Journal, 10(2), 39-52. https://doi.org/10.24191/smrj.v10i2.5226

Pamornmast, C., Jermsittiparsert, K., \& Sriyakul, T. (2013). Exchange Rate and Nation's Export Competitiveness: An Empirical Discourse Analysis. Asian Social Science, 9(13), 147-156. https://doi.org/10.5539/ass.v9n13p147

Panayotou, T. (1997). Demystifying the environmental Kuznets curve: turning a black box into a policy tool. Environment and Development Economics, 2(4), 465-484. https://doi.org/10.1017/S1355770X97000259

Patnaik, D., \& Pillai, A. (2017). Responsiveness of the Indian Tax System: A Time Series Analysis from 1990 to 2010. Economy, 4(1), 1-6. https://doi.org/10.20448/journal.502.2017.41.1.6

Pazil, N. H. A. (2018). Face, Voice and Intimacy in Long-Distance Close Friendships. International Journal of Asian Social Science, 8(11), 938-947. https://doi.org/10.18488/journal.1.2018.811.938.947

Pedroni, P. (2001a). Fully modified OLS for heterogeneous cointegrated panels. In Nonstationary panels, panel cointegration, and dynamic panels (pp. 93-130). Emerald Group Publishing Limited. https://doi.org/10.1016/S0731-9053(00)15004-2

Pedroni, P. (2001b). Purchasing power parity tests in cointegrated panels. Review of Economics and Statistics, 83(4), 727-731. https://doi.org/10.1162/003465301753237803

Pedroni, P. (2004). Panel cointegration: asymptotic and finite sample properties of pooled time series tests with an application to the PPP hypothesis. Econometric Theory, 20(3), 597-625. https://doi.org/10.1017/S0266466604203073

Perera, C. R., Johnson, L. W., \& Hewege, C. R. (2018). A review of organic food consumption from a sustainability perspective and future research directions. International Journal of Management and Sustainability, 7(4), 204-214. https://doi.org/10.18488/journal.11.2018.74.204.214

Perera, W. S. (2018). An Analysis of the Behaviour of Prime Lending Rates in Sri Lanka. Asian Journal of Economics and Empirical Research, 5(2), 121-138.

Pesaran, M. H. (2004). General diagnostic tests for cross section dependence in panels. CESifo Working Paper No 1229. Center for Economic Studies and IFO Institute (CESifo), Munich. 
Phillips, P. C., \& Hansen, B. E. (1990). Statistical inference in instrumental variables regression with I(1) processes. The Review of Economic Studies, 57(1), 99-125. https://doi.org/10.2307/2297545

Saidi, K., \& Mbarek, M. B. (2017). The impact of income, trade, urbanization, and financial development on CO 2 emissions in 19 emerging economies. Environmental Science and Pollution Research, 24(14), 12748-12757.

Shahbaz, M., Khraief, N., Rehman, I. U., \& Zaman, K. U. (2016). Does Globalization Affect Economic Growth? The Role of Financial Development and Capital Use in Pakistan. International Journal of Economics and Empirical Research (IJEER), 4(8), 430-449. https://doi.org/10.1016/j.eneco.2016.11.008

Shahbaz, M., Nasreen, S., Ahmed, K., \& Hammoudeh, S. (2017). Trade openness-carbon emissions nexus: The importance of turning points of trade openness for country panels. Energy Economics, 61, 221-232.

Shahzad, S. J. H., Kumar, R. R., Zakaria, M., \& Hurr, M. (2017). Carbon emission, energy consumption, trade openness and financial development in Pakistan: A revisit. Renewable and Sustainable Energy Reviews, 70, 185-192. https://doi.org/10.1016/j.rser.2016.11.042

Sharif, A., Afshan, S., \& Qureshi, M. A. (2019). Idolization and ramification between globalization and ecological footprints: evidence from quantile-on-quantile approach. Environmental Science and Pollution Research, 1-21. https://doi.org/10.1007/s11356-019-04351-7

Sharif, A., Raza, S. A., Ozturk, I., \& Afshan, S. (2019). The dynamic relationship of renewable and non-renewable energy consumption with carbon emission: A global study with the application of heterogeneous panel estimations. Renewable Energy, 133, 685-691. https://doi.org/10.1016/j.renene.2018.10.052

Westerlund, J. (2007). Testing for error correction in panel data. Oxford Bulletin of Economics and Statistics, 69(6), 709-748. https://doi.org/10.1111/j.1468-0084.2007.00477.x

Wizarat, S., \& Hye, Q. (2010). Financial reforms and industrial sector growth: bound testing analysis for Pakistan. South East European Journal of Economics and Business, 5(2), 75-81. https://doi.org/10.2478/v10033-010-0017-0

Wu, Y., \& Pei, Z. (2018). An Investigation of Critical Thinking Manifested in the Questions of EFL Textbooks for Tertiary-Level English Majors of China. American Journal of Education and Learning, 3(2), 72-84. https://doi.org/10.20448/804.3.2.72.84

Xu, Q., \& Zhang, H. (2018). Optimal Bid Strategies in Crowdsourcing Contest Based on Multi-Attribute Auctions. International Journal of Emerging Trends in Social Sciences, 4(2), 67-74. https://doi.org/10.20448/2001.42.67.74 